\title{
RADIOCARBON DATING OF IRON ARTIFACTS
}

\section{RICHARD G. CRESSWELL}

\author{
IsoTrace Laboratory, 60 St. George Street, Toronto, Ontario M5S 1A7 Canada
}

\begin{abstract}
During the late 1960s, N. J. van der Merwe (1969) obtained ${ }^{14} \mathrm{C}$ measurements on 11 iron pieces, ranging in carbon content from medium carbon $(0.22 \%)$ wrought iron $(1.2 \mathrm{~kg}$ used) to high carbon $(3.2 \%)$ cast iron $(30 \mathrm{~g})$, thereby demonstrating the feasibility of the technique for ${ }^{14} \mathrm{C}$ dating iron. In the early 1980 s, Sayre et al. (1982) repeated two of van der Merwe's measurements, and carried out two analyses on a recently rediscovered Elizabethan(?) iron bloom. Thirty grams were required of this medium carbon wrought iron to obtain an age using small proportional counters. A number of iron artifacts have recently been analyzed by accelerator mass spectrometry (AMS) at IsoTrace. Samples ranged in size from $3.4 \mathrm{~g}$ of a medium carbon $(-0.4 \%)$ wrought iron bloom to $274 \mathrm{mg}$ for a high carbon $(1.79 \%)$ wootz steel fragment. AMS now permits analysis of samples that previously were too small or too valuable to be analyzed. For larger samples, multiple analyses can reveal variations that may aid the evaluation of sample history.
\end{abstract}

\section{INTRODUCTION}

During the manufacture of iron in its various forms (wrought iron, steel, cast iron), carbon is incorporated into the structure in solid solution in ferrite (up to 0.035\%), as cementite ( $\mathrm{Fe}_{3} \mathrm{C}: 6.7 \%$ $\mathrm{C})$, as discrete graphite flakes or chunks and as precipitates of carbides and carbonitrides from the supersaturated solution. A reliable date may be obtained on this carbon if it can be shown to be contemporaneous with manufacture. Some of the possible sources of contamination, both ancient and modern have been discussed elsewhere (Cresswell 1991). With good archaeometallurgical constraints, however, a meaningful date may be obtained from the carbon in the iron. Associated material may be intrusive, dating a more recent use of the artifact, whereas in many cases, no associated carbonaceous material may be available as a substitute.

The first use of ${ }^{14} \mathrm{C}$ dating of iron was conceived by $\mathrm{K}$. K. Turekian, who believed the technique could distinguish non-radiogenic fuels (i.e., coal) from radiogenic, which might indicate the date of manufacture of an artifact (van der Merwe 1963). In the 1960s, N. J. van der Merwe built, at Yale, an extraction, purification and preparation line to analyze iron artifacts. Several iron samples were put through the system (Table 1). The use of 0.5 - and 1.5 -liter $\mathrm{CO}_{2}$ gas proportional counters at the Yale Geochronometric Laboratories required that samples contain $500 \mathrm{mg}$ of carbon. This severe limitation on sample size, requiring up to $1 \mathrm{~kg}$ of iron, restricted the technique's applicability, despite the demonstrated feasibility as a dating tool (van der Merwe 1969).

In the late 1970s, small proportional counters allowed a decrease in sample size by a factor of 50 . Van der Merwe instigated a program to date iron at Pretoria, but this work was discontinued because of poor accuracy (van der Merwe, personal communication 1989). A study on an iron bloom thought to be of Elizabethan origin, and associated with the Arctic voyages of Sir Martin Frobisher in the 1570s, was carried out by collaborators from the Smithsonian Institution and Brookhaven National Laboratory (Sayre et al. 1982), using small counters (Harbottle, Sayre \& Stoenner 1979). Sample sizes were still on the order of tens of grams, and poor precision limited the usefulness of the dates (Table 1). Although suggested, AMS studies on even smaller sample sizes (Sayre et al. 1982), were not undertaken.

\section{SAMPLE PREPARATION AND CARBON EXTRACTION}

A carbon extraction, purification and preparation line was built and tested at IsoTrace (Cresswell 1987), based on the design of van der Merwe (1969). The smaller sample requirements (2-5 mg) 
TABLE 1. Artifacts Analyzed Prior To This Study

\begin{tabular}{lcccc}
\hline Artifact & $\% \mathrm{C}^{*}$ & $\begin{array}{c}\text { Weight } \\
(\mathrm{g})\end{array}$ & $\begin{array}{c}\text { Age** } \\
(\mathrm{yr} \mathrm{BP})\end{array}$ & Ref. $^{\dagger}$ \\
\hline Saugus cast iron & 2.9 & 380 & $350 \pm 60$ & 1 \\
& 3.73 & $\sim 10$ & $469 \pm 144$ & 2 \\
Redding cast iron & 2.3 & 231.9 & $180 \pm 60$ & 1 \\
& 3.98 & $\sim 10$ & $285 \pm 145$ & 2 \\
Hopewell cast iron & 2.0 & 289.2 & $200 \pm 60$ & 1 \\
Scottish iron nails & 0.22 & 1232.1 & $1850 \pm 80$ & 1 \\
Sian cast iron & 3.2 & 187.4 & $2060 \pm 80$ & 1 \\
Hunan cast iron & 1.9 & 200.4 & $400 \pm 60$ & 1 \\
Hunan cast iron & 3.1 & 46.4 & $2380 \pm 80$ & 1 \\
Szechuan cast iron & 2.6 & 32.7 & $2130 \pm 100$ & 1 \\
Yugoslavian steel sword & 0.66 & 216.0 & $2130 \pm 60$ & 1 \\
South Dakota cast iron & 3.0 & 198.0 & $\geq 25,000^{\ddagger}$ & 1 \\
North Dakota cast iron & 2.7 & 245.6 & $\geq 6700^{\ddagger}$ & 1 \\
Frobisher Bloom \#1 & 0.051 & $\approx 30$ & $679 \pm 133$ & 2 \\
& -0.127 & & & \\
Frobisher Bloom \#1 & 0.048 & $\approx 30$ & $792 \pm 107$ & 2 \\
& -0.061 & & & \\
\hline
\end{tabular}

*Estimated values based on combustion yields

**The ages obtained by van der Merwe were used to corroborate the suspected dates of manufacture of the samples. The nature of the ${ }^{14} \mathrm{C}$ calibration curve does not give specific dates for most samples, and precise calendric dates are not possible for the precisions cited. The Hunan sample gives a date 4 to 10 centuries too young, based on stylistic grounds. It may be a Ming copy, or from a repaired section of the statue.

${ }^{\dagger} 1-\mathrm{van}$ der Merwe and Stuiver (1968); 2-Sayre et al. (1982)

tSome coal or coke was used in the manufacture of these ingots. Assuming a mixed fuel was used, the ratios of coke to charcoal would have been ca. 95:5 and 55:45 for the South and North Dakota samples, respectively.

for AMS measurements have allowed a more compact design, in which the sample can undergo carbon extraction, purification and target preparation in a continuous operation (Fig. 1).

The sample is first checked for rust and surface contaminants and cleaned by scraping and abrading until bright metal is exposed. After a cold ultrasonic bath in 10\% nitric acid to remove the outer surface and any adhering abrasion grit, the sample is washed with de-ionized water, followed by methanol, and then dried in an oven at $80^{\circ} \mathrm{C}$ overnight.

If the sample weighs $<2 \mathrm{~g}$, Leco ${ }^{\circledast}$ iron chip accelerator is added, and this is loaded in a zirconia combustion boat into a quartz tube in the quartz combustion chamber (Fig. 1). The sample sits within the coil furnace at $500^{\circ} \mathrm{C}$; the line is evacuated and maintained at $<10^{-3}$ torr for $30 \mathrm{~min}$ to pump away surface adsorbed air and to obtain a good seal at the ground glass joint.

The coil for the induction furnace is moved to a position covering the sample and ultra-pure oxygen (Canox Limited) is admitted via a flow meter. The outlet valve is opened when an overpressure of 900 torr is achieved in the line, and the oxygen allowed to stabilize. The dry ice/ethanol trap and variable-temperature (VT) trap (modified after the designs of van der Merwe (1969) and DesMarais (1978)) are cooled to $-78^{\circ} \mathrm{C}$ and $-180^{\circ} \mathrm{C}$, respectively, and the induction furnace turned on. 


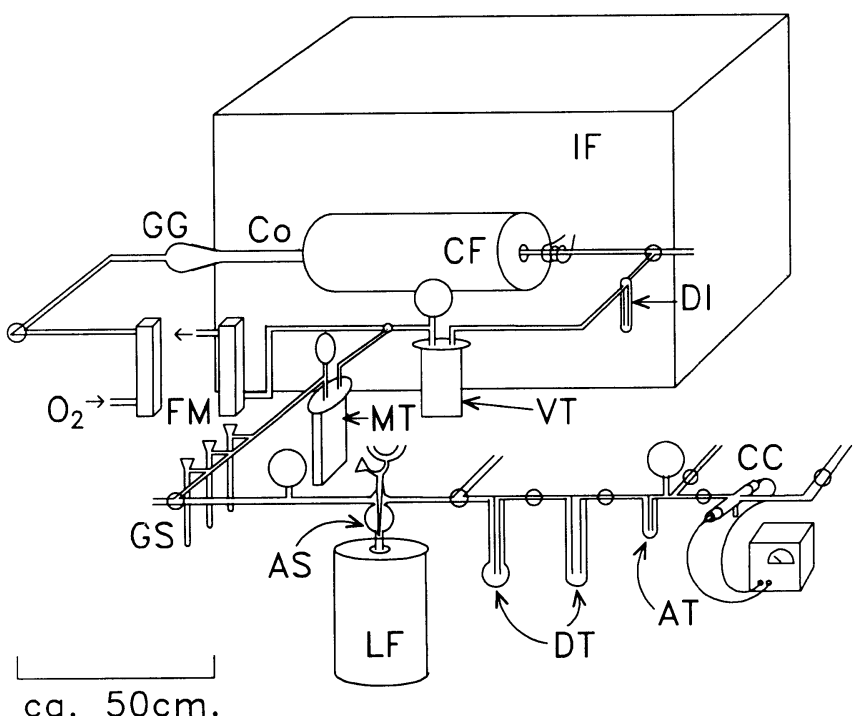

Fig. 1. Schematic of the iron combustion/ carbon extraction, purification and preparation line. See text for details. AS-acetylene synthesis; AT-acetylene trap; CC-cracking chamber; $\mathrm{CF}$-coil furnace; $\mathrm{Co}-\mathrm{Combustion}$ chamber; DI-dry ice/alcohol cooled trap; DT-drying traps; FM-flow meter; GGground glass joint; GS-gas storage vials; IF-induction furnace; LF-lithium furnace; MT-measuring trap; $\mathrm{O}_{2}$-oxygen inlet; VT-variable temperature trap. Unmarked large circles represent vacuum gauges; small circles are valves. All unmarked ends lead to the high-vacuum pump.

As the sample is heated, carbon diffuses to the surface of the molten metal and it and the iron are oxidized. These exothermic reactions drive the dominant reactions into the $\mathrm{CO}_{2}$ stability field, with generally $>90 \%$ recovery of the carbon. $\delta^{13} \mathrm{C}$ values for analyzed samples indicate that negligible fractionation of the isotopes occurs at this stage. Oxygen flow is adjusted to maintain positive pressure, although the speed of oxidation often requires that the outlet valve is shut as the sample combusts. Combustion takes $c a .10 \mathrm{~min}$, as the iron oxidizes to wustite, then hematite, loses its ferromagnetic properties, and ceases to induct the current from the coil.

Once the sample is exhausted, the VT trap is isolated and the oxygen pumped away. The trap is warmed to $-50^{\circ} \mathrm{C}$ and the $\mathrm{CO}_{2}$ transferred to the measuring trap.

The $\mathrm{CO}_{2}$ can then be stored in gas vials, or added to heated lithium metal to create lithium carbide in the lithium furnace. Water is added to create acetylene, which is dried, trapped and measured. Aliquots of gas are admitted to the cracking chamber, where a $1 \mathrm{kV} \mathrm{AC}$ discharge across two aluminum target slugs acting as electrodes, causes the acetylene to dissociate, depositing carbon on the surface (Beukens, Gurfinkel \& Lee 1986). These targets are then analyzed for ${ }^{14} \mathrm{C}$ by AMS.

A sample of over $2 \mathrm{mg}$ of carbon is currently preferred for cracking. This allows a further order of magnitude reduction in original sample size over that of proportional counters. Because the actual size of sample is dependent on the carbon content of the iron, low carbon (0.05\%) wrought iron will need to weigh at least $5 \mathrm{~g}$, whereas a high carbon cast iron of $2 \%$ carbon need only weigh $100 \mathrm{mg}$.

\section{BACKGROUNDS}

The use of coke in modern blast furnaces provides a source of background material for ${ }^{14} \mathrm{C}$ analysis: we obtained run-of-mill steel samples from the Stelco Steel Works in Hamilton, Ontario for this purpose, although a danger of contamination from modern sources cannot be entirely eliminated. Table 2 shows some results.

Analysis of a high carbon cast iron (TO-285) indicates that contamination from modern sources is below $0.7 \mathrm{pMC}$. All artifacts analyzed in this study underwent conversion from $\mathrm{CO}_{2}$ to cracked 
TABLE 2. Samples Analyzed to Check Contamination

\begin{tabular}{|c|c|c|c|c|c|}
\hline $\begin{array}{l}\text { IsoTrace } \\
\text { No. }\end{array}$ & Sample & $\% \mathrm{C}$ & $\begin{array}{l}\text { Weight } \\
\text { (g) }\end{array}$ & $\begin{array}{c}{ }^{14} \mathrm{C} \text { activity } \\
\text { (pMC) }\end{array}$ & $\begin{array}{c}\text { Apparent } \\
\text { age (yr BP) }\end{array}$ \\
\hline \multicolumn{6}{|c|}{ A. Analysis of background samples using medical-grade oxygen (see text) } \\
\hline \multirow[t]{2}{*}{ TO-128-2 } & FUM 175958 & & & & \\
\hline & Disko Island iron & $\approx 0.65$ & 3.193 & $2.67 \pm 0.07$ & $29,090 \pm 340$ \\
\hline $\begin{array}{l}\text { TO-285 } \\
\text { TO-314-3 }\end{array}$ & $\begin{array}{l}5665-1 \text { cast iron } \\
\text { Stelco steel }\end{array}$ & 4.87 & 2.35 & $0.64 \pm 0.06$ & $40,630 \pm 760$ \\
\hline TO-314-5 & $\begin{array}{l}\text { C1090 (88-09-01) } \\
\text { C1090 (88-11-18) } \\
\text { (+ iron chip) }\end{array}$ & $\begin{array}{r}0.960 \\
0.960 \\
<0.001\end{array}$ & $\begin{array}{l}2.0 \\
0.700 \\
5.88\end{array}$ & $\begin{array}{l}2.13 \pm 0.10 \\
2.20 \pm 0.07\end{array}$ & $\begin{array}{l}30,910 \pm 360 \\
30,660 \pm 240\end{array}$ \\
\hline \multicolumn{6}{|c|}{ B. Re-analysis using ultra-pure oxygen (see text) } \\
\hline TO-314-6 & $\begin{array}{l}\text { C1090 (90-06-05) } \\
\text { (+ iron chip) }\end{array}$ & $\begin{array}{r}0.960 \\
<0.001\end{array}$ & $\begin{array}{l}0.755 \\
5.34\end{array}$ & $0.82 \pm 0.08$ & $38,630 \pm 780$ \\
\hline $\mathrm{RC}-23^{*}$ & $5665-1$ cast iron & 4.87 & 1.72 & $0.47 \pm 0.07$ & $43,107 \pm 1268$ \\
\hline
\end{tabular}

*Processed from sample to target on the line shown in Figure 1. All other samples underwent $\mathrm{CO}_{2}$ to target conversion on the line described in Beukens, Gurfinkel and Lee (1986).

target on the line described by Beukens, Gurfinkel and Lee (1986). This was the model for the gas conversion section, which was only recently added to complete the line shown (Fig. 1). The date obtained for the cast iron on this line (RC-23: Table 2B) is similar at the 2 o limits. For small samples, iron chips are used to increase the load sufficiently for induction. To test the contribution of ${ }^{14} \mathrm{C}$ to the sample from this source, two high carbon steels (C1090) were run on an earlier line both with (TO-314-5) and without (TO-314-3) the chips (Table 2A). The agreement between the two dates indicates that the chip is ${ }^{14} \mathrm{C}$-free, with a total carbon contribution of $<100 \mathrm{ppm}$. The ages indicated a low level of contamination, which was tested with a piece of native iron from Disko Island, west Greenland. This test gave comparable results, suggesting a consistent source of contamination that was tracked to the oxygen used. Repeat analyses on different sample sizes, for differing lengths of time and flow-rates indicated that the oxygen contained appreciable ${ }^{14} \mathrm{C}$, with a contribution equivalent to $0.586 \pm 0.171 \mathrm{ml}$ modern $\mathrm{CO}_{2}$ per liter of oxygen used. Between 1 and 4 liters could be flushed over the sample during analysis, resulting in a small but significant contribution. The use of high purity oxygen appears to have alleviated this problem (TO-314-6: Table 2B:), with levels now equivalent to $<0.0523 \pm 0.090 \mathrm{ml} \mathrm{liter}^{-1}$. Further purification is required, and is currently being tested. The levels of contamination, however, are sufficiently low $(<0.5$ $\mathrm{pMC}$ ) and not significant for the dating of iron artifacts, the history of which begins no earlier than 4 ka BP (Tylecote 1976).

\section{CONTAMination}

Unlike most carbonaceous materials that may suffer contamination from modern or later carbon sources, iron is more prone to dilution from older carbon sources, e.g., coal, coke, lime and the reworking of older artifacts (e.g., cofusion or welding). The Romans used coal for forging fires (Tylecote 1986), and the Chinese smelted ores with coal from at least the 4th century AD (Needham 1958). Fortunately, most smelting was carried out with charcoal, and usually, the preference was for freshly cut wood (Forbes 1964). Generally, it was not until the Industrial Revolution in Europe in the 18th century and the dissemination of technology to other parts of the 
world in the 19th century that coke was used universally. Charcoal has continued to be used in some places. Bloomery furnaces fired by charcoal produced $6 \%$ of all wrought iron produced in the United States in 1856, whereas Sweden still used charcoal-fired furnaces up to World War I (Tylecote 1976). Isolated occurrences of charcoal-fired furnaces may still be found today (e.g., in southern Africa (van der Merwe \& Scully 1971)), though not producing on a large scale.

High $(>0.1 \%)$ sulfur content of iron may indicate the use of coal. Bog iron ore and siderite $\left(\mathrm{FeCO}_{3}\right)$ ores, however, may yield appreciable sulfur from pyrite, even if charcoal were used as the fuel, and the carbon would be contemporaneous with manufacture (Tylecote 1976).

With the development of mass production and blast-furnace techniques, in China in the 4th century $\mathrm{BC}$ and in Europe during the Middle Ages, and the production of cast iron, free-flowing iron and slag were needed, and the use of lime as a flux became more common (Tylecote 1976). Most of the carbon from the lime would be lost during low-temperature $\left(\mathrm{ca} .750^{\circ} \mathrm{C}\right)$ reduction. Some carbon from the lime could be incorporated into the iron together with that from the fuel, whereas the calcium would flux into the slag. Thus, a high Ca content $(>10 \%)$ in slag inclusions may indicate the use of a flux that could also serve to invalidate the ${ }^{14} \mathrm{C}$ age.

Thorough metallographic examination is desirable prior to ${ }^{14} \mathrm{C}$ analysis. If possible, this should include X-radiology, to determine whether multiple pieces were used and chemical analysis of the iron and slag inclusions to help constrain the components of the original charge. If one can establish the contemporaneity of the carbon and minimal contamination, a reliable date might be obtained. If the piece is too small, or too valuable, one may have to rely upon educated guesses based on historical information.

\section{ANALYSIS OF THREE IRON ARTIFACTS}

\section{Frobisher Bloom No. 2}

Besides the aforementioned bloom dated by the Brookhaven/Smithsonian group, three other blooms associated with the Canadian voyages of Sir Martin Frobisher have been recovered, all from the small island of Kodlunarn, in Frobisher Bay, Baffin Island, Northwest Territories. Unglik (1987) described one of these blooms, and Harbottle, Cresswell and Stoenner (1992) discussed the initial results. This obloid, 5.4-kg bloom has a circumference ranging from 12 to $17 \mathrm{~cm}$ and a height of $9 \mathrm{~cm}$. The primitive metallurgy suggests a pre-Elizabethan, perhaps Norse, origin, which agrees with the dates obtained for the previously analyzed bloom (790-545 (2 o) cal BP: Table 1$)$. Both sulfur $(<0.1 \%)$ and calcium $(<2 \% \mathrm{CaO})$ are very low, indicating that neither coal nor flux was used in its manufacture (Unglik 1987) and that ${ }^{14} \mathrm{C}$ dating might be feasible.

We have dated the new bloom at IsoTrace, in collaboration with W. W. Fitzhugh at the Smithsonian Institution, to help evaluate its origin and compare it to the other bloom. The initial sample consisted of $1.338 \mathrm{~g}$ of low-carbon $(\approx 0.3 \%)$ steel cut from the outer edge of a slab sectioned by Parks Canada (TO-712: Table 3). The calibrated date, $1310-1190$ cal BP, is considerably older than expected, superficially supporting the idea of discovery, or reworking, of Norse remains. During the slicing of the bloom, a fragment of charcoal was exposed; this was dated to 944-800 cal BP, further supporting the Norse origin. A third, unrelated piece of carbonaceous material of organic origin from the same site, but not associated with the bloom, however, gave an age of 25,640 \pm $220 \mathrm{BP}$, indicating the use of coal at the site. The finite date reflects contamination from a recent source. Ships' records report coal as cargo for one of the Frobisher voyages, although its use, whether for heating or forging, has yet to be ascertained. 
TABLE 3. Iron Artifacts Analyzed at IsoTrace

\begin{tabular}{clcccc}
\hline $\begin{array}{c}\text { IsoTrace } \\
\text { No. }\end{array}$ & Sample description & $\begin{array}{c}\text { Weight } \\
(\mathrm{g})\end{array}$ & $\begin{array}{c}\mathrm{CO}_{2} \\
(\mathrm{cc})\end{array}$ & $\begin{array}{c}{ }^{14} \mathrm{C} \text { age } \\
(\mathrm{yr} \mathrm{BP})\end{array}$ & Cal BP* \\
\hline TO-712 & $\begin{array}{l}\text { FROB-2-V2-1B } \\
\text { Near-surface sample } \\
\text { from Frobisher bloom }\end{array}$ & 1.34 & 3.7 & $1340 \pm 70$ & $1310-1190$ \\
TO-712-2 & $\begin{array}{l}\text { FROB-2-V2-1A } \\
\text { Internal sample }(\approx \mathrm{cm})\end{array}$ & 3.21 & 9.7 & $550 \pm 60$ & $643-595$ \\
TO-712-3 & $\begin{array}{l}\text { FROB-2-H1-2A } \\
\text { Internal sample }(\sim 5 \mathrm{~cm})\end{array}$ & 3.40 & 7.3 & $500 \pm 60$ & $550-508$ \\
TO-347 & $\begin{array}{l}\text { Charcoal } \\
\text { from cut FROB-2-V2 }\end{array}$ & 0.472 & n.a. & $970 \pm 60$ & $944-800$ \\
TO-1085 & $\begin{array}{l}\text { MOD-19-8-73 } \\
\text { Sri Lankan wootz steel }\end{array}$ & 0.274 & 7.1 & $980 \pm 40$ & $938-912$ \\
TO-1995 & $\begin{array}{l}\text { MIT Luristan steel } \\
\text { TO-1996 }\end{array}$ & 1.440 & 9.9 & $2880 \pm 60$ & $3087-2942^{* *}$ \\
\hline
\end{tabular}

*Calibrated at the $68 \%$ confidence limit by the program C14CAL by R. P. Beukens using the bidecadal smoothed data set of Stuiver and Pearson (1986).

**Using the bidecadal data set of Pearson and Stuiver (1986).

We have since analyzed two further samples, both from within the bloom: TO-712-2, ca. $2 \mathrm{~cm}$ from the surface, and TO-712-3, $5 \mathrm{~cm}$ into the bloom (Table 3). The ages agree at the $63 \%$ confidence limit, although the calibrated ages are significantly different at the $95 \%$ limit. These dates are closer to Elizabethan in origin, and suggest multiple sources of carbon used for smelting. Interestingly, the averaged age of $832 \pm 50 \mathrm{BP}$ for the four samples is within $2 \sigma$ of the ages obtained on the larger samples $(30 \mathrm{~g})$ by the Brookhaven/Smithsonian group. The old age on the near-surface sample suggests refiring of the bloom in a coal-fired furnace, prior to forging, with diffusion of older carbon into the surface. We hope to analyze the other blooms to help resolve this problem.

\section{Sri Lankan Wootz Steel}

We have dated $274 \mathrm{mg}$ of high-carbon (1.79\%) wootz steel from central-eastern Sri Lanka to 980 \pm 40 BP (938-912 cal BP: Table 3). This is the only measurement made on wootz steel, and helps constrain the historical development, both of the region and of wootz metal. The piece is from the site of a current irrigation development on the Maduru Oyo River, a project that will drown the remains of previous dams and settlements uncovered during excavations for the current project. These settlements appear to date back to the 5th century $\mathrm{AD}$, but little information is available on the archaeology, except that settlement ceased in the 13th century, and the dams from previous occupations have all but been washed away by the river (S. Brown, personal communication 1991).

Wootz metal is ideal for ${ }^{14} \mathrm{C}$ dating. While the exact production method remains enigmatic, the process is known to have been small-scale, with accounts of its production indicating either single (Percy 1864) or repeated (Richardson 1934) carburization of small iron cakes with wood, rice husks, bamboo or leaves. The initial iron cakes were usually bloomery iron, smelted in charcoalfired furnaces (Percy 1864). The contemporaneity of the carbon with the manufacture of the iron is therefore ensured (Coghlan 1977). Analytically, this sample is significant in that it is the smallest 
piece of iron dated, three orders of magnitude smaller than was required by the first measurements by van der Merwe.

\section{Luristan Daggers}

An alleged Luristan dagger has been in the collection at the Royal Ontario Museum (ROM) for a number of decades. The authenticity of this piece, which stylistically resembles bronze daggers of the 1st millennium BC, and its possible relationship to a second dagger held by the Massachusetts Institute of Technology (MIT), required confirmation. A fragment from the MIT dagger was submitted, and a 6-mm core was drilled from the ROM specimen.

These medium-carbon $(0.3-1.0 \% \mathrm{C})$ steels yielded ages of $2880 \pm 60 \mathrm{BP}$ for the MIT dagger and $2940 \pm 60$ BP for the ROM dagger, indicating an early and likely coeval origin. At that time, the Luristan region was a center for metallurgy, and used charcoal-fired furnaces as the basis of a smelting technology (Tylecote 1976). Microprobe analyses of the pieces indicate low sulfur (not detected) and calcium $(<5 \% \mathrm{CaO})$; hence, the date is likely to be contemporaneous with manufacture of these blades.

\section{CONCLUSIONS}

${ }^{14} \mathrm{C}$ analysis should be carried out in conjunction with detailed metallurgical studies to help ascertain the origin of iron. Many iron artifacts contain separate pieces, welded or forged together. Each may have a different origin that may be easily ascertained by metallography. Chemical analysis may also help unravel the origin of an artifact's raw materials: the ore and the fuel, and whether a flux was used. High sulfur content may indicate a significant coal component to the carbon, which would essentially falsify the ${ }^{14} \mathrm{C}$ date obtained. High calcium may indicate the use of a lime flux, and the potential for erroneous dates. Only with careful consideration of the archaeometallurgical history of the artifact can meaningful discussion of the resulting dates be undertaken.

Early ${ }^{14} \mathrm{C}$ analysis of iron required that substantial amounts of material be sacrificed to obtain sufficient carbon for accurate dating. Small counters alleviated the sample size problem, but the results suffered from poor statistics. AMS has enabled us to date even smaller samples without losing precision on the date. Prior to this study, only 12 iron artifacts had been analyzed for ${ }^{14} \mathrm{C}$, with sample sizes ranging from $10 \mathrm{~g}$ to over $1 \mathrm{~kg}$ (Table 1 ). We have built and tested an iron combustion, carbon extraction, purification and preparation line at IsoTrace, which has proven to be satisfactory for the analysis of some historical irons. Further research is continuing to reduce backgrounds, and increase precision and reliability for very young samples. Sample size is still determined by the carbon content of the sample: $5 \mathrm{~g}$ of a low carbon $(0.05 \%)$ wrought iron is required, whereas only $100 \mathrm{mg}$ of a $2 \%$ cast iron is necessary.

In 1968, van der Merwe and Stuiver expressed the hope that dating of iron would become routine at ${ }^{14} \mathrm{C}$ laboratories, helping constrain the history of metallurgy by dating the metals themselves. The measurement of ${ }^{14} \mathrm{C}$ in iron is now routinely carried out at IsoTrace; interpretation of results, and constraining the history of iron may require a little more time!

\section{ACKNOWLEDGMENTS}

I wish to thank all my colleagues at IsoTrace for their help and time, in particular, Roelf Beukens, Ted Litherland and John Rucklidge. Thanks also go to Carl Bowen in sample preparation and to Larry Pavlish for further discussion and stimulus. This work was supported in part by the Natural Science and Engineering Research Council of Canada through operating grants to J. C. Rucklidge 
and A. E. Litherland, and an infrastructure grant to the IsoTrace Laboratory. The paper has benefitted from a review by David Killick.

\section{REFERENCES}

Beukens, R. P., Gurfinkel, D. M. and Lee, H. W. 1986 Progress at the IsoTrace radiocarbon facility. In Stuiver, M. and Kra, R. S., eds., Proceedings of the 12th International ${ }^{14} \mathrm{C}$ Conference. Radiocarbon 28 (2A): 229-236.

Coghlan, H. H. 1977 Notes on Prehistoric and Early Iron in the Old World. Oxford, Oxprint Ltd.: 144 p.

Cresswell, R. G. (ms.) 1987 Radio-carbon dating of iron using accelerator mass spectrometry. M.Sc. dissertation, University of Toronto: $158 \mathrm{p}$.

1991 The radiocarbon dating of iron artefacts using accelerator mass spectrometry. Historical Metallurgy 25: 76-85.

DesMarais, D. J. 1978 Variable temperature trap for the separation of gas mixtures. Analytical Chemistry 50: 1405-1406.

Forbes, R. J. 1964 Studies in Ancient Technology 9. Leiden, E. J. Brill: 295 p.

Harbottle, G., Cresswell, R. G. and Stoenner, R. W. 1992 Carbon-14 dating of iron blooms from Kodlunarn Island. In Fitzhugh, W. W. and Olin, J. S., eds., The Archaeology of the Frobisher Voyages: A Contribution to the Archaeology of Kodlunarn Island, Frobisher Bay, Baffin Island, Northwest Territories, Canada. Washington, Smithsonian Institution Press. In press.

Harbottle, G., Sayre, E. V. and Stoenner, R. W. 1979 Carbon-14 dating of small samples by proportional counters. Science 206: 683-685.

Needham, J. 1958 The Development of Iron and Steel Technology in China. London, Newcomen Society: $107 \mathrm{p}$.

Pearson, G. W. and Stuiver, M. 1986 High-precision calibration of the radiocarbon time scale, 500-2500 BC. In Stuiver, M. and Kra, R. S., eds., Proceedings of the 12 th International ${ }^{14} \mathrm{C}$ Conference. Radiocarbon 28(2B): 839-862.

Percy, J. 1864 Metallurgy. II (3): 773-776.

Richardson, H. C. 1934 Iron prehistoric and ancient. American Journal of Archaeology 38(4): 555-583.

Sayre, E. V., Harbottle, G., Stoenner, R. W., Washburn, W., Olin, J. S. and Fitzhugh, W. W. 1982 The carbon-14 dating of an iron bloom associated with the voyages of Sir Martin Frobisher. American Chemical Society Symposium Series 176: 441-451.

Stuiver, M. and Pearson, G. W. 1986 High-precision calibration of the radiocarbon time scale, AD 1950500 BC. In Stuiver, M. and Kra, R. S., eds., Proceedings of the 12 th International ${ }^{14} \mathrm{C}$ Conference. Radiocarbon 28(2B): 805-838.

Tylecote, R. F. 1976 A History of Metallurgy. London, The Metals Society: $182 \mathrm{p}$.

1986 The Prehistory of Metallurgy in the British Isles. London, The Institute of Metals: $257 \mathrm{p}$.

Unglik, H. (ms.) 1987 Metallurgical study of a recently recovered iron bloom and associated finds from Kodlunarn Island, Frobisher Bay, Canada. Manuscript on file, National Parks and Sites, Environment Canada - Parks, Ottawa: 152 p.

van der Merwe, N. J. 1963 Wanted. Current Anthropology 4: 375-376.

1969 The Carbon-14 Dating of Iron. Chicago, University of Chicago Press: $137 \mathrm{p}$.

van der Merwe, N. J. and Scully, R. T. K. 1971 The Phalaborwa story: Archaeological and ethnographic investigation of a South African Iron Age group. World Archaeology 3: 178-196.

van der Merwe, N. J. and Stuiver, M. 1968 Dating iron by the carbon-14 method. Current Anthropology 9: 48-53. 